\title{
25 Research Suare \\ Effect of Ventilation Quantity on Electron Transfer Capacity and Spectral Characteristics of Humic Substances During Sludge Composting
}

\section{Zhihan Tan}

Guilin University of Technology

Hongxiang Zhu

Chinese Research Academy of Environmental Sciences

Xiaosong He

Chinese Research Academy of Environmental Sciences

\section{Beidou Xi}

Guilin University of Technology

\section{Yuxin Tian}

Guilin University of Technology

Xiaojie Sun ( $\nabla$ sunxiaojie@glut.edu.cn )

Guilin University of Technology

Hongxia Zhang

Guilin University of Technology

Quanyi Ouche

Guilin University of Technology

\section{Research Article}

Keywords: Composting, Electron transfer capability, Humic acids, Fulvic acids, Excitation-emission matrix parallel factor analysis

Posted Date: February 23rd, 2022

DOI: https://doi.org/10.21203/rs.3.rs-1242952/v1

License: (c) (i) This work is licensed under a Creative Commons Attribution 4.0 International License. Read Full License 


\section{Abstract}

Humic substances (HSs) plays an important role in the degradation of organic pollutants and the passivation of heavy metals in soil, and their environmental effects are closely related to their electron transfer capacity (ETC). However, the effect of ventilation quantity on ETC of compost-derived HA is unclear. In this study, HS was extracted from compost with different ventilation quantities $(0.1,0.2$, and $0.3 \mathrm{~L} \mathrm{~kg}^{-1}$ dry matter (DM) $\mathrm{min}^{-1}$, denoted as VQ1, VQ2, and VQ3, respectively) and divided into humic acids (HAs) and fulvic acids (FAs). Their ETC and electron recycling rate (ERR) were measured by electrochemical method. The structure and composition of HS and its evolution in composting process were analyzed by excitation-emission matrix spectroscopy, Fourier transform infrared spectroscopy, and ultraviolet and visible spectrophotometry. The influence of HS composition characteristics on ETC and ERR was investigated by correlation analysis. Results showed that the increase in the ventilation quantity did not change the composition structure of HS, but it affected the formation of HS. With the composting process, the electron donating capacity (EDC), electron accepting capacity (EAC), ETC, and ERR of the three piles VQ1, VQ2, and VQ3 showed an increasing trend. By contrast, the pile VQ2 with ventilation quantity of $0.2 \mathrm{~L} \mathrm{~kg}^{-1} \mathrm{DM} \mathrm{min}{ }^{-1}$ enhanced EAC, ETC, and ERR of HA and FA mainly because of the accelerating consumption of lignin, protein-like, and aliphatic substances and the generation of aromatic and fulvic-like substances. Such transformation improved the humification degree. Correlation analysis showed that EDC, ETC, and ERR were correlated with the generation of FA, and EAC was correlated with the generation of $\mathrm{HA}$.

\section{Introduction}

Composting is an effective method to treat organic solid waste (Chen et al., 2020). Compost products not only play an important role in promoting plant growth, improving soil properties, and enhancing soil carbon sequestration (Jurado et al., 2015; Piccolo et al., 2004; Said-Pullicino et al., 2007) but also have great potential in remediation of soil pollution due to humic substances (HSs) derived from the composting process (Madejón et al., 2016; Yuan et al., 2016).

HS is a complex macromolecular organic matter, including humic acid (HA), fulvic acid (FA), and humin (Guo et al., 2019). HS has electron transfer capacity (ETC) because it has a large number of functional groups with redox activity. HS can transfer electrons between microorganisms and terminal electron receptors as electron shuttles, which mediates the passivation of heavy metals and the degradation of refractory organic pollutants; thus, HS plays an important role in environmental pollution remediation (Wu

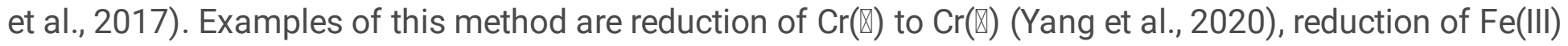
to $\mathrm{Fe}(\mathbb{\nabla})$ (Stern et al., 2018), reduction of nitrobenzene to aniline (Yuan et al., 2017), and reduction and dechlorination of pentachlorophenol (Zhao et al., 2020). HS also has the characteristic of transferring electrons repeatedly and can further accelerate the transformation rate of pollutants (Xu et al., 2009). Electron recycling rate (ERR) is often used to measure the durative of electron transfer (Yuan et al., 2012). The application of compost in soil remediation actually depends on the ETC and ERR of HS in compost. The value of compost in soil remediation is higher when the ETC and ERR values are stronger (Zhang et 
al., 2021). Therefore, ETC and ERR of HS are important indicators to determine its environmental effect (Azim et al., 2018).

Ventilation quantity is an important parameter that affects composting process (Gao et al., 2010). Insufficient ventilation can cause anaerobic phenomenon, but excessive ventilation can decrease the compost temperature and may not be conducive to the degradation of organic matter (Ahn et al., 2007). The heat and temperature of the reactor can be adjusted by regulating the ventilation volume; thus, the degradation of organic matter and the formation of HS are affected (Chen et al., 2020). Most current studies on ventilation quantity focus on the effect of ventilation quantity on physicochemical properties, such as maintaining the temperature of compost, accelerating the degradation of organic matter, and improving germination index (Zang et al., 2016). However, the effect of ventilation quantity on the ETC of HS during composting is unclear.

The main objectives of this study were as follows. (1) The evolution of ETC during composting with different ventilation quantities was investigated by electrochemical method. (2) The changes in organic composition and structure during composting with different ventilation quantity were analyzed using spectral analysis method to clarify the key affecting factors of ETC of HS. The results provide scientific basis for the application of compost products and the improvement in pollution remediation efficiency of compost products.

\section{Materials And Methods}

\subsection{Composting process and sample collection}

Municipal sludges were from a sewage treatment plant in Guilin, China. The sludge and rice bran were evenly mixed at $3: 1(\mathrm{~m} / \mathrm{m})$ ratio and then placed into three identical reactors (total effective volume of approximately $50 \mathrm{~L}, \Phi 37 \times 57 \mathrm{~cm}$ ) for the continuous aeration composting. The aeration quantities of the three piles were set as $0.1,0.2$, and $0.3 \mathrm{~L} \mathrm{~kg}^{-1} \mathrm{DM} \mathrm{min}^{-1}$, which were denoted as VQ1, VQ2, and VQ3, respectively. Each pile was turned over once a week. Samples were collected on days $0,3,6,9,12,15,21$, 30 , and 40 . One part of the samples was stored directly in a $-20^{\circ} \mathrm{C}$ freezer, and the other part was freezedried and passed through a 60-mesh sieve. After screening, the samples were stored in the $-20{ }^{\circ} \mathrm{C}$ freezer for further analysis.

\subsection{Extraction and separation of the HA and FA}

The extraction and evaluation methods of HS refer to the methods of Song (Song et al., 2015a) and Zhou (Zhou et al., 2014). The initial extraction of HS was by lye extraction. The extracted lye was $0.1 \mathrm{~mol} / \mathrm{L}$ $\mathrm{Na}_{2} \mathrm{P}_{2} \mathrm{O}_{7}$ and $0.1 \mathrm{~mol} / \mathrm{L} \mathrm{NaOH}$ mixed in $1: 1$ solution, and then, it was placed into the horizontal constant temperature oscillator to oscillate for $24 \mathrm{~h}$. The mixture was centrifuged at 10,000 rpm for $20 \mathrm{~min}$, and the centrifuged supernatant was filtered through a $0.45 \mu \mathrm{m}$ filtration membrane. The precipitate obtained after centrifugation (4,000 rpm for $15 \mathrm{~min}$ ) was crude $\mathrm{HA}$, and the supernatant was crude $\mathrm{FA}$ after the $\mathrm{pH}$ of the filtrate was adjusted to 1-2. 
The HA was redissolved with $0.1 \mathrm{~mol} / \mathrm{L} \mathrm{NaOH}$, supernatant was collected after centrifugation $(10,000$ rpm for $20 \mathrm{~min}$ ), and pH of supernatant was adjusted to 1-2 with $6 \mathrm{~mol} / \mathrm{L} \mathrm{HCl}$, followed by static settlement for $6 \mathrm{~h}$. It was centrifugated again, and the supernatant was discarded. Pure HA was obtained after four times washing with distilled water and $0.1 \mathrm{~mol} / \mathrm{L} \mathrm{HCl}$. The crude FA was passed through the XAD-8 resin column, and the FA was trapped in the resin and then eluted in the resin column with 0.1 $\mathrm{mol} / \mathrm{L} \mathrm{NaOH}$. The solution was passed into IR120 hydrogen cation exchange resin column to eliminate the interference of sodium ion. Purified FA was obtained after being freeze-dried. HA and FA were stored in a $4{ }^{\circ} \mathrm{C}$ refrigerator for further analysis (Ma et al., 2001).

\subsection{ETC and ERR measurements}

The ETC includes electron accepting capacity (EAC) and electron donating capacity (EDC), both of which can be measured by electrochemical methods (Bi et al., 2013). Electrochemical measurements were performed on an electrochemistry workstation CHI660 (Chenhua Co., Ltd., Shanghai, China). The electrochemical detection method uses a three-electrode electrolytic cell device with working electrode (glassy carbon electrode) opposite electrode (platinum column electrode) and reference electrode (Ag/ AgCl electrode) (Tang et al., 2019). The purified HA and FA were determined by voltammetry, and 2 $\mathrm{g} / \mathrm{L} \mathrm{ABTS}$ and $2 \mathrm{~g} / \mathrm{L}$ DQ were used as mediators for oxidation and reduction, respectively (Bi et al., 2013). During the detection, the electrolytic device should be installed first, and $2 \mathrm{~mL}$ neutral phosphate buffer and $2 \mathrm{~mL} \mathrm{KCl}$ solution should be added to the electrolytic cell, and nitrogen should be used for $5 \mathrm{~min}$ to drain oxygen. Nitrogen should also be used during the detection to ensure the stable reading of the detection data. The oxidation potential and reduction potential were set at 0.61 and $-0.49 \mathrm{~V}$, respectively, for baseline detection. When the baseline was stable, $1 \mathrm{~mL}$ of mediating agent was added into the measuring device for further detection (ABTS was added for EDC detection, and DQ was added for EAC detection). After the reaction was stable, diluted HA and FA samples were added to keep TOC at $50 \mathrm{mg} / \mathrm{L}$. The ETC was calculated using the following formula:

$$
\mathrm{ETC}(\mathrm{EDC} \text { or } \mathrm{EAC})=\frac{\mathrm{A}_{\mathrm{P}}}{\left(\mathrm{e} \times \mathrm{N}_{\mathrm{A}} \times \mathrm{M}_{\mathrm{C}}\right)}
$$

The unit of EAC and EDC was $\mu \mathrm{mol} \mathrm{e}^{-} \cdot(\mathrm{g} \mathrm{C})^{-1}, \mathrm{~A}_{\mathrm{p}}$ was the Coulomb integral of compost organic matter oxidation curve or compost organic matter reduction curve, and the unit of Coulomb was (C), $\mathrm{N}_{A}$ was Avogadro constant $\left(6.02 \times 10^{23} \mathrm{~mol}^{-1}\right)$, e was the charge per unit electron $\left(1.6 \times 10^{-19} \mathrm{C}\right), \mathrm{M}_{\mathrm{C}}$ was the content of carbon in the reaction system $\left(3.5 \times 10^{-4} \mathrm{~g}\right)$, and ETC of compost sample was the sum of EDC and EAC.

ERR refers to the number of electrons that HS can steadily accept and supply as an electron shuttle. ERR is commonly used to represent its detection device. The potential-step method was used to detect HA and $\mathrm{FA}$, and $0.5-1 \mathrm{~mL}$ of purified $\mathrm{HA}$ and FA were diluted and added into $2 \mathrm{~mL}$ DMSO and $1 \mathrm{~mL}$ in the electrolyte solution of $1 \mathrm{mmol} / \mathrm{L}$ sodium perchlorate. The total TOC was kept at $50 \mathrm{mg} / \mathrm{L}$, the oxidation 
and reduction potentials were set at 0.61 and $-0.49 \mathrm{~V}$, respectively, and the number of cycles was set to 3 . The ERR was calculated using the following formula:

$\mathrm{ERR}=\frac{\mathrm{Q}_{\text {cycle 2 }}+\mathrm{Q}_{\text {cycle 3 }}}{2 \mathrm{Q}_{\text {cycle 1 }}} \times 100 \%$.

\subsection{Structure and component characterization of organic compounds}

\subsubsection{Fluorescence spectra}

The composition and evolution of HS in composting process are often detected by excitation-emission matrix (EEM) spectroscopy (Marhuenda-Egea et al., 2007). In this study, the EEM fluorescence spectra were recorded by an F98 fluorescence spectrophotometer (Linguang, Shanghai, China). The excitation wavelength (Ex) was set at 200-450 nm, and the emission wavelength (Em) was set at $280-550 \mathrm{~nm}$. Slit broadband was $5 \mathrm{~nm}$. The scanning speed was set at $3000 \mathrm{~nm} / \mathrm{min}$.

The fluorescence spectra image of HS was transformed into a matrix, and MATLAB R2018 was used for PARAFAC analysis. DOMFluor and EEMscat toolkit (www.models.life.ku.dk) were used to separate the components and calculate the content of each component in the sample. Before separation, the blank sample was deducted to reduce the influence of Raman scattering (Stedmon et al., 2003). Humification index (HIX) and fluorescence index (FI) were calculated by pickpeaks function. HIX was an important index to reflect the humification degree of compost, while FI could reflect the contribution degree of aromatic substances and nonaromatic substances to compost (He et al., 2013; Wang et al., 2016).

\subsubsection{Ultraviolet and visible spectrophotometry}

Ultraviolet and visible (UV-Vis) spectrophotometry was performed with UV-2820 UV-Vis spectrophotometer (Unique, USA). TOC was diluted to $20 \mathrm{mg} / \mathrm{L}$ before scanning, and pure water was used as blank control group. The scanning wavelength ranged from $190 \mathrm{~nm}$ to $700 \mathrm{~nm}$, and the scanning interval was $1 \mathrm{~nm}$.

\subsubsection{Fourier transform infrared spectroscopy}

Fourier transform infrared spectroscopy (FT-IR) using an infrared spectrophotometer (Is10, ThermoFisher, USA) for detection. Freeze-dried sample and $\mathrm{KBr}$ after grinding were mixed with a mass ratio of 1:100 and then ground with agate mortar. The mixed samples after grinding were placed into a tablet pressing mold for pressing. The pressed glass slides were uniformly transparent and placed into infrared spectrograph to determine the scanning range of $450-4000 \mathrm{~cm}^{-1}$, the number of scanning was set to 14 , and the resolution was $2 \mathrm{~cm}^{-1}$.

\subsection{Data analysis}




\section{Results And Discussion}

\subsection{ETC and ERR of HA and FA}

The ETC of HA and FA samples are shown in Fig. 1. The EDC and EAC of HA show an overall upward trend. The EDC of HA of VQ1, VQ2, and VQ3 gradually increases from day $0(41.52,39.41$, and 38.06 $\mu \mathrm{mol} \mathrm{e}^{-} / \mathrm{g}$ C, respectively) to the maximum on day $40\left(44.15,57.12\right.$, and $57.66 \mu \mathrm{mol} \mathrm{e}^{-} / \mathrm{g} \mathrm{C}$, respectively); the EAC gradually increases from day $0\left(40.45,39.76\right.$, and $39.91 \mu \mathrm{mol} \mathrm{e}^{-} / \mathrm{g} \mathrm{C}$, respectively) to the maximum on day $40\left(48.02,55.96\right.$, and $52.90 \mu \mathrm{mol} \mathrm{e}^{-} / \mathrm{g} \mathrm{C}$, respectively). The increase in EDC and EAC may be due to the oxidation of lignin-like matter and the increases in phenols, quinones, and carboxyl groups in HA during composting (He et al., 2019). The increasing trend of the ETC of HA in the three piles is similar to that of EDC and EAC; it reaches the maximum value on the 40th day, and it reaches 92.17, 113.08 , and $110.56 \mu \mathrm{mol} \mathrm{e}^{-} / \mathrm{g} C$ for the three piles, respectively. The ETC of HA in VQ2 and VQ3 is stronger than that in VQ1, while the difference between VQ2 and VQ3 is not obvious.

The EDC of FA fluctuates from day $0\left(24.22,26.92\right.$, and $\left.27.37 \mu \mathrm{mol} \mathrm{e}^{-} / \mathrm{g} \mathrm{C}\right)$ to day $40(31.95,35.34$, and $34.56 \mu \mathrm{mol} \mathrm{e}^{-} / \mathrm{g} \mathrm{C}$ ), which may be due to the degradation of organic matter that increases the reducing group content in FA. EAC increases from day $0\left(40.45,24.83\right.$, and $\left.26.68 \mu \mathrm{mol} \mathrm{e}^{-} / \mathrm{g} \mathrm{C}\right)$ to day 40 (48.02, 33.84 , and $36.54 \mu \mathrm{mol} \mathrm{e}^{-} / \mathrm{g} \mathrm{C}$ ), which is similar to EDC. The EAC of FA increases gradually, which is possibly due to the decomposition of protein-like substances and aromatic polycondensation during the composting process (He et al., 2019). The ETC of FA in the three piles shows an increasing trend, and it reaches the maximum value at day $40\left(65.3,72.45\right.$, and $\left.71.86 \mu \mathrm{mol} \mathrm{e}^{-} / \mathrm{g} \mathrm{C}\right)$.

In summary, the ETC of FA and HA in VQ2 is stronger than that in VQ1 and VQ3, which may be due to that VQ2 improves the degradation and humification process and promotes the oxidation of organic matter and the formation of HSs. In addition, a slight difference is observed in the contribution of EAC and EDC to ETC in HA and FA, which indicates that the oxidation and reduction capacities of HS are the same. This result is different from those of the study of He et al. (2014).

The ERR of HA and FA in the three piles is shown in Fig. 2. HA and FA show a slightly declining trend first and then a rising trend. The ERR of HA is in the range of $45.82-70.59 \%$, and that of FA is in the range of 51.88-72.37\%. Only a slight difference is observed between FA and HA in ERR. However, FA has a slightly higher ERR than HA. This result may be due to the fact that FA contains a large number of unstable electron groups and has a stronger cyclic reaction capacity.

\subsection{Composition and structure evolution of HS and its influence on ETC}

\subsubsection{EEM fluorescence spectra}


Four components were identified through PARAFAC analysis (Fig. 3). Component 1 (C1, Ex=345 nm, $E m=430 \mathrm{~nm}$ ) shows one excitation peak and one emission peak ascribe to HA peak ( $E x=300-370 \mathrm{~nm}$, $\mathrm{Em}=420-510 \mathrm{~nm}$ ). The result is similar to the humic-like substance peak discovered by Zhou et al. (2019). Component 2 (C2, Ex=400 nm, Em=485 nm) also shows a single excitation peak and an emission peak located in the humic-like substance peak region, but its Ex has a blue shift. Component 3 (C3, $E x=320 \mathrm{~nm}, E m=389 \mathrm{~nm})$ peak is located in the traditional fulvic-like region $(E x=310-369 \mathrm{~nm}, E m=370-$ $450 \mathrm{~nm}$ ), which corresponds to fulvic-like substances. The peak of component 4 (C4, Ex=240 nm, $E m=351 \mathrm{~nm})$ is located in the T-peak region $(E x=270-280 \mathrm{~nm}, E m=320-350 \mathrm{~nm})$ with blue shift in $E x$ and red shift in Em, which mainly reflects protein-like substances such as tryptophan (Zhang et al., 2021).

HA and FA of the three piles can be divided into four components by PARAFAC analysis, and content changes of different components are shown in Fig. 4. The C4 of the HA decreases gradually with the composting process, which implies that protein-like substances are degraded by microorganisms, and the C4 content in VQ1, VQ2, and VQ3 decreases to $4 \%, 1 \%$, and 4\%, respectively. By contrast, VQ2 has a higher utilization efficiency of organic matter. The content of C4 in FA increases first and then decreases, but the content of $\mathrm{C} 4$ in FA of the three piles decreases to the minimum at the end of composting.

The content of C3 in HA increases first and then decreases, and it increases slightly at the end of composting compared with the initial value, which may be due to the formation of FA from small molecular substances in composting process. Then, the FA gradually transforms into humic-like substances or HS precursors. However, a slight change is observed in C3 content of FA in the three piles, which may be due to the continuous conversion and degradation of FA (Huang et al., 2021). The content of $\mathrm{C} 2$ of $\mathrm{HA}$ and FA in the three piles increases, which means the gradual formation of humic-like substances during composting. The $\mathrm{C} 1$ of $\mathrm{HA}$ at the end of composting is insignificantly different from the initial value, but the $\mathrm{C} 1$ of $\mathrm{FA}$ shows a significant increase, which is probably due to $\mathrm{C} 1$ being closer to the fulvic-like substance in the fluorescence composition. The formation rates of $\mathrm{C} 1, \mathrm{C} 2$, and C3 in VQ2 are the highest, which implies that the degradation of protein and the production of humic-like substances are enhanced in pile VQ2.

The HIX of HA and FA in piles VQ1, VQ2, and VQ3 increases steadily (Fig. 5), and the humification degree of HA is higher than that of FA. Therefore, the composting process increases the humification degree of HA and FA (Jacquin et al., 2017). As shown in Fig. 5, the FI of all three piles gradually increases (McKnight et al., 2001). This result may be due to the microbial degradation and polymerization of organic substances into aromatic structure, such as aromatic groups and benzene ring, which improves the aromatic properties of HA and FA. The FI value of FA is higher than that of HA, which means that aromatic substances in FA contribute more to compost maturity.

\subsubsection{UV-Vis spectra}

The UV-Vis spectra of HA and FA of the three piles are shown in Fig. 6. The UV-Vis absorption values of the three piles have similar trend, and all of them tend to decrease with the increase in wavelength. HA and FA have an absorption peak at approximately $260-280$ band, which is caused by the light absorption 
of lignosulfonate and its derivatives in the sample, and its absorbance value will increase with the continuous generation of unsaturated conjugated bond $\mathrm{C}=\mathrm{C} / \mathrm{C}=\mathrm{O}$ ( $\mathrm{Li}$ et al., 2010). Except for FA of VQ3, the absorption values of HA and FA at the absorbance of $280 \mathrm{~nm}$ increase, which implies that the aromaticity and unsaturation of HS increases, and the degree of humification increases with the progress of composting.

The SUVA 254 and the SUVA 280 are generally used to represent the content change of unsaturated $\mathrm{C}=\mathrm{C}$ bond and the change in aromatic molecular weight (Albrecht et al., 2011). During composting, the condensation of lignin and amino acid will increase the HS content, and the absorption value of the SUVA $_{254}$ will also increase as well (Song et al., 2015b). The absorption value of the SUVA 280 is related to the molecular weight of organic matter (Ren et al., 2019). Both indicators can represent degree of humification. As shown in Fig. 6, SUVA 254 and SUVA 280 of HA and FA for VQ1 and VQ2 show an overall increasing trend, which implies that their HS content is increased. The HA of VQ3 shows a fluctuating rise, but its FA shows a fluctuating decline. According to EEM spectrum analysis, this phenomenon may be due to that excessive aeration in the early stage of compost results in a large amount of FA of VQ3, but the unstable structure of FA leads to a low conversion rate in the stable period.

The $E_{250} / E_{365}$ is the ratio of lignin to carboxylic acid, and it is often used to indicate the molecular weight of organic matter (Strobel et al., 2001). The $\mathrm{E}_{253} / \mathrm{E}_{203}$ can be used to characterize the types of substituents on the aromatic ring. A lower $E_{253} / E_{203}$ value indicates that the substituents are stable groups such as aliphatic chains, while a higher $E_{253} / E_{203}$ value indicates that the substituents are active groups such as hydroxyl, carboxyl, and carbonyl groups (He et al., 2014). As shown in Fig. 7, the $E_{250} / E_{365}$ value of $H A$ and $F A$ of the three piles decreases with the composting process. The $E_{250} / E_{365}$ value of HA (2.54-2.56) at the end of composting is lower than that of FA (3.14-3.66), and the decrease in VQ2 is larger, which indicates that more macromolecular HAs are generated in the HS of VQ2 (SaidPullicino et al., 2007). As shown in Fig. 6, the $E_{253} / E_{203}$ value of $H A$ fluctuates during the composting process, and its increase is most significant in VQ2. Unlike $H A$, the $E_{253} / E_{203}$ value of $F A$ in all the three piles shows a continuous upward trend. The interaction between HS and heavy metals in soil mainly depends on the transfer of electrons of active groups, and remediation of soil pollution can be achieved through chelating and redox effects of heavy metals (Chen et al., 2019). The change in the $E_{253} / E_{203}$ indicates that soil heavy metals can be better passivated by compost products derived from VQ2.

The ratio of the integral of the $275-295 \mathrm{~nm}$ absorption band to the integral of the $350-400 \mathrm{~nm}$ absorption band is denoted as $\mathrm{Sr}$, which is negatively correlated with the molecular weight of HS and can be used to characterize the degree of aromatization in HS (Spencer et al., 2012). Fig. 9 shows that the Sr value of HA and FA in the three heaps decreases continuously with the composting process, which implies that macromolecular aromatic substances increase continuously during composting.

\subsubsection{FT-IR results}


The FT-IR results of HA and FA of the three piles are shown in Fig. 9. The absorption peaks of HA and FA in the three piles are mainly $3439-3280 \mathrm{~cm}^{-1}, 2957-2917 \mathrm{~cm}^{-1}, 2856-2842 \mathrm{~cm}^{-1}, 1657-1646 \mathrm{~cm}^{-1}$, $1547-1513 \mathrm{~cm}^{-1}, 1402 \mathrm{~cm}^{-1}, 1255-1241 \mathrm{~cm}^{-1}$, and 1043-1026 cm-1. The wave peaks of 3439-3280 $\mathrm{cm}^{-1}$ in the three piles gradually weaken, which means that $\mathrm{O}-\mathrm{H}$ functional groups such as hydroxyl group on HA and FA are decreasing during the composting process (Peltre et al., 2017; Soobhany et al., 2017; Sun et al., 2014). The absorption peak of $2957-2917 \mathrm{~cm}^{-1}$ may be caused by the $\mathrm{C}-\mathrm{H}$ antisymmetric vibration of lignin and $\mathrm{C}-\mathrm{H}$ stretching vibration of aliphatic group. The peak of HA and FA in the three piles weakens and disappears on day 12. Therefore, the fat substances are completely consumed during the cooling period of compost. The wave peaks of $1657-1646 \mathrm{~cm}^{-1}$ is the $C=C$ stretching vibration of aromatic group, and the growth degree of VQ2 and VQ3 in this section is higher than that of VQ1, which proves a higher degree for the humification (Masmoudi et al., 2013). The absorption peak of $1547-1513 \mathrm{~cm}^{-1}$ may be generated by $\mathrm{N}-\mathrm{H}$ and $\mathrm{C}=\mathrm{N}$ stretching vibration, $\mathrm{FA}$ in the VQ2 and VQ3 performs more significant in this section, and HA performs more significant in VQ2 (Merlo et al., 2020). The peak of $1402 \mathrm{~cm}^{-1}$ may be caused by the stretching vibration of carboxylic acids, and VQ1 and VQ3 are stronger than VQ2 at $1255-1241 \mathrm{~cm}^{-1}$, which may be caused by the stretching of lignin-related functional groups. HA and FA of the three piles have little difference at $1043-1026 \mathrm{~cm}^{-1}$, which may be generated by $\mathrm{C}-\mathrm{O}$ stretching vibration of polysaccharides or alcohols, where VQ2 has the best effect. The analysis of the wave peak above shows that VQ2 has a higher degree of humification.

3.4 Relationship among ETC, fluorescence characteristics, and maturity degree of HA and FA in compost with different ventilation quantities

Correlation analysis was conducted to elucidate the relationship among ETC, ERR, maturity degree, and fluorescence characteristics of HA and FA. As shown in Fig. 10, components in HA of VQ1 are insignificantly correlated with changes in EDC, EAC, and ETC. Meanwhile, ERR and C4 are significantly negatively correlated. This result may be due to that the decomposition of protein-like substances will make HS generate more active reversible groups (Amir et al., 2010). HIX is significantly positively correlated with ERR and negatively correlated with C4. Therefore, the decomposition of small molecules such as proteins during the composting process would increase the degree of humification and improve ERR of HS. FI, Sr, and HIX for FA in VQ1 are significantly positively correlated with EDC, ETC, and ERR, respectively.

Sr is positively correlated EAC with HA in VQ2 $(P<0.01)$, and HIX is negatively correlated with EAC in FA $(P<0.01)$. Therefore, the formation of $H A$ will promote the enhancement in $E A C$, while the formation of $F A$ will increase EDC and ETC. The correlation heat map of VQ3 is similar to that of VQ2, which also proves that EDC and ETC are related to FA generation in compost from different composting conditions and EAC is related to HA generation (Li et al., 2021).

\section{Conclusion}


The EDC, EAC, ETC, and ERR of three piles showed an upward trend with the progress of composting. By contrast, VQ2 enhanced EAC, ETC, and ERR of HA and FA. This result was mainly due to that VQ2 promoted the consumption of lignin protein, the generation of aliphatic and aromatic substances, and the maturity of compost. Correlation analysis showed that EDC, ETC, and ERR were correlated with the generation of FA, and EAC was correlated with the generation of HA. Therefore, sludge compost with ventilation quantity of $0.2 \mathrm{~L} \mathrm{~kg}^{-1} \mathrm{DM} \mathrm{min}{ }^{-1}$ could enhance the ETC of HSs.

\section{Declarations}

Ethics approval Not applicable.

Consent to participate All authors agree to participate in the editing of the paper.

Consent for publication All authors agree to publish this manuscript in the journal.

Author contribution This manuscript was contributed by all the authors. Zhihan Tan®Conceptualization, Xiaojie Sun and Hongxiang Zhu: Funding acquisition, Xiaojie Sun , Beidou Xi: Project administration, Quanyi Ouche and Yuxin Tian: Data curation, software and methodology, Zhihan Tan, Xiaojie Sun, Hongxia Zhang and Xiaosong He : Writing-review \& editing. All authors read and approved the final manuscript.

Funding information This work was financially supported by Natural Science Foundation of Guangxi (No. 2018GXNSFGA281001); Science and Technology Major Project of Guangxi (No. AA18118013); Guangxi Science and Technology Project (No. AD18126018)

Competing interests The authors declare no competing interests.

Availability of data and materials The datasets used or analysed during the current study are available from the corresponding author on reasonable request.

\section{References}

1. Ahn HK, Richard TL, Choi HL (2007) Mass and thermal balance during composting of a poultry manure-Wood shavings mixture at different aeration rates. Process Biochem 42:215-223

2. Albrecht R, Le Petit J, Terrom G, Périssol C (2011) Comparison between UV spectroscopy and nirs to assess humification process during sewage sludge and green wastes co-composting. Bioresour Technol 102:4495-4500. https://doi.org/10.1016/j.biortech.2010.12.053

3. Amir S, Jouraiphy A, Meddich A, El Gharous M, Winterton P, Hafidi M (2010) Structural study of humic acids during composting of activated sludge-green waste: Elemental analysis, FTIR and 13C NMR. J Hazard Mater 177:524-529. https://doi.org/10.1016/j.jhazmat.2009.12.064

4. Azim K, Soudi B, Boukhari S, Perissol C, Roussos S, Alami IT (2018) Composting parameters and compost quality: a literature review. Organic agriculture 8:141-158 
5. Bi R, Lu Q, Yu W, Yuan Y, Zhou S (2013) Electron transfer capacity of soil dissolved organic matter and its potential impact on soil respiration. J Soils Sediments 13:1553-1560

6. Chen T, Zhang S, Yuan Z (2020) Adoption of solid organic waste composting products: A critical review. J Clean Prod 272:122712. https://doi.org/10.1016/j.jclepro.2020.122712

7. Chen W, Luo S, Du S, Zhang M, Cheng R, Wu D (2020) Strategy to Strengthen Rural Domestic Waste Composting at Low Temperature: Choice of Ventilation Condition. Waste Biomass Valoriz 11:66496665. https://doi.org/10.1007/s12649-020-00943-4

8. Chen Y, Chen Y, Li Y, Wu Y, Zeng Z, Xu R, Wang S, Li H, Zhang J (2019) Changes of heavy metal fractions during co-composting of agricultural waste and river sediment with inoculation of Phanerochaete chrysosporium. J Hazard Mater 378:120757. https://doi.org/10.1016/j.jhazmat.2019.120757

9. Gao M, Li B, Yu A, Liang F, Yang L, Sun Y (2010) The effect of aeration rate on forced-aeration composting of chicken manure and sawdust. Bioresour Technol 101:1899-1903. https://doi.org/10.1016/j.biortech.2009.10.027

10. Guo X, Liu H, Wu S (2019) Humic substances developed during organic waste composting: Formation mechanisms, structural properties, and agronomic functions. Sci Total Environ 662:501510. https://doi.org/10.1016/j.scitotenv.2019.01.137

11. He X, Xi B, Cui D, Liu Y, Tan W, Pan H, Li D (2014) Influence of chemical and structural evolution of dissolved organic matter on electron transfer capacity during composting. J Hazard Mater 268:256263. https://doi.org/10.1016/j.jhazmat.2014.01.030

12. He X, Xi B, Li X, Pan H, An D, Bai S, Li D, Cui D (2013) Fluorescence excitation-emission matrix spectra coupled with parallel factor and regional integration analysis to characterize organic matter humification. Chemosphere 93:2208-2215. https://doi.org/10.1016/j.chemosphere.2013.04.039

13. He X, Xi B, Pan H, Li X, Li D, Cui D, Tang W, Yuan Y (2014) Characterizing the heavy metal-complexing potential of fluorescent water-extractable organic matter from composted municipal solid wastes using fluorescence excitation-emission matrix spectra coupled with parallel factor analysis. Environ Sci Pollut Res 21:7973-7984. https://doi.org/10.1007/s11356-014-2751-9

14. He X, Yang C, You S, Zhang H, Xi B, Yu M, Liu S (2019) Redox properties of compost-derived organic matter and their association with polarity and molecular weight. Sci Total Environ 665:920-928. https://doi.org/10.1016/j.scitotenv.2019.02.164

15. Huang W, Li Y, Liu X, Wang W, Wen P, Yu Z, Zhou S (2021) Linking the electron transfer capacity with the compositional characteristics of dissolved organic matter during hyperthermophilic composting. Sci Total Environ 755:142687. https://doi.org/10.1016/j.scitotenv.2020.142687

16. Jacquin C, Lesage G, Traber J, Pronk W, Heran M (2017) Three-dimensional excitation and emission matrix fluorescence (3DEEM) for quick and pseudo-quantitative determination of protein- and humiclike substances in full-scale membrane bioreactor (MBR). Water Res 118:82-92. https://doi.org/10.1016/j.watres.2017.04.009 
17. Jurado MM, Suárez-Estrella F, López MJ, Vargas-García MC, López-González JA, Moreno J (2015) Enhanced turnover of organic matter fractions by microbial stimulation during lignocellulosic waste composting. Bioresour Technol 186:15-24

18. Li G, Zhu Q, Niu Q, Meng Q, Yan H, Wang S, Li Q (2021) The degradation of organic matter coupled with the functional characteristics of microbial community during composting with different surfactants. Bioresour Technol 321:124446. https://doi.org/10.1016/j.biortech.2020.124446

19. Li M, He X, Liu J, Xi B, Zhao Y, Wei Z, Jiang Y, Su J, Hu CM (2010) Study on the characteristic UV absorption parameters of dissolved organic matter extracted from chicken manure during composting. Spectroscopy and Spectral Analysis 30:3081-3085 (in Chinese)

20. Ma H, Allen HE, Yin Y (2001) Characterization of isolated fractions of dissolved organic matter from natural waters and a wastewater effluent. Water Res 35:985-996. https://doi.org/10.1016/S00431354(00)00350-X

21. Madejón P, Domínguez MT, Díaz MJ, Madejón E (2016) Improving sustainability in the remediation of contaminated soils by the use of compost and energy valorization by Paulownia fortunei. Sci Total Environ 539:401-409. https://doi.org/10.1016/j.scitotenv.2015.09.018

22. Marhuenda-Egea FC, Martínez-Sabater E, Jordá J, Moral R, Bustamante MA, Paredes C, Pérez-Murcia MD (2007) Dissolved organic matter fractions formed during composting of winery and distillery residues: Evaluation of the process by fluorescence excitation-emission matrix. Chemosphere 68:301-309. https://doi.org/10.1016/j.chemosphere.2006.12.075

23. Masmoudi S, Jarboui R, El Feki H, Gea T, Medhioub K, Ammar E (2013) Characterization of olive mill wastes composts and their humic acids: stability assessment within different particle size fractions. Environ Technol 34:787-797

24. McKnight DM, Boyer EW, Westerhoff PK, Doran PT, Kulbe T, Andersen DT (2001) Spectrofluorometric characterization of dissolved organic matter for indication of precursor organic material and aromaticity. Limnol Oceanogr 46:38-48. https://doi.org/10.4319/lo.2001.46.1.0038

25. Merlo C, Vázquez C, Iriarte AG, Romero CM (2020) Chemical and spectroscopic characterization of humic substances from sediment and riparian soil of a highly polluted urban river (Suquía River, Córdoba, Argentina). Int J Sedim Res 35:287-294. https://doi.org/10.1016/j.ijsrc.2019.10.004

26. Peltre C, Gregorich EG, Bruun S, Jensen LS, Magid J (2017) Repeated application of organic waste affects soil organic matter composition: Evidence from thermal analysis, FTIR-PAS, amino sugars and lignin biomarkers. Soil Biol Biochem 104:117-127.

https://doi.org/10.1016/j.soilbio.2016.10.016

27. Piccolo A, Spaccini R, Nieder R, Richter J (2004) Sequestration of a biologically labile organic carbon in soils by humified organic matter. Clim Change 67:329-343

28. Ren X, Wang Q, Awasthi MK, Zhao J, Tu Z, Li R, Wen L, Zhang Z (2019) Effect of tertiary-amine bentonite on carbon transformation and global warming potential during chicken manure composting. J Clean Prod 237:117818. https://doi.org/10.1016/j.jclepro.2019.117818 
29. Said-Pullicino D, Erriquens FG, Gigliotti G (2007) Changes in the chemical characteristics of waterextractable organic matter during composting and their influence on compost stability and maturity. Bioresour Technol 98:1822-1831. https://doi.org/10.1016/j.biortech.2006.06.018

30. Song C, Li M, Xi B, Wei Z, Zhao Y, Jia X, Qi H, Zhu C (2015a) Characterisation of dissolved organic matter extracted from the bio-oxidative phase of co-composting of biogas residues and livestock manure using spectroscopic techniques. Int Biodeterior Biodegrad 103:38-50. https://doi.org/10.1016/j.ibiod.2015.03.032

31. Song C, Li M, Xi B, Wei Z, Zhao Y, Jia X, Qi H, Zhu C (2015b) Characterisation of dissolved organic matter extracted from the bio-oxidative phase of co-composting of biogas residues and livestock manure using spectroscopic techniques. Int Biodeterior Biodegrad 103:38-50. https://doi.org/10.1016/j.ibiod.2015.03.032

32. Soobhany N, Gunasee S, Rago YP, Joyram H, Raghoo P, Mohee R, Garg VK (2017) Spectroscopic, thermogravimetric and structural characterization analyses for comparing Municipal Solid Waste composts and vermicomposts stability and maturity. Bioresour Technol 236:11-19. https://doi.org/10.1016/j.biortech.2017.03.161

33. Spencer RG, Butler KD, Aiken GR (2012) Dissolved organic carbon and chromophoric dissolved organic matter properties of rivers in the USA.Journal of Geophysical Research: Biogeosciences 117

34. Stedmon CA, Markager S, Bro R (2003) Tracing dissolved organic matter in aquatic environments using a new approach to fluorescence spectroscopy. Mar Chem 82:239-254. https://doi.org/10.1016/S0304-4203(03)00072-0

35. Stern N, Mejia J, He S, Yang Y, Ginder-Vogel M, Roden EE (2018) Dual Role of Humic Substances As Electron Donor and Shuttle for Dissimilatory Iron Reduction. Environ Sci Technol 52:5691-5699. https://doi.org/10.1021/acs.est.7b06574

36. Strobel BW, Hansen HC, B, Borggaard OK, Andersen MK, Raulund-Rasmussen K (2001) Composition and reactivity of $\mathrm{DOC}$ in forest floor soil solutions in relation to tree species and soil type. Biogeochemistry 56:1-26

37. Sun X, Li G, Xiao A, Shi H, Wang Y, Li Y (2014) [Analysis on the impact of composting with different proportions of corn stalks and pig manure on humic acid fractions and IR spectral feature]. Guang pu xue yu guang pu fen $x i=$. Guang pu 34:2413-2418

38. Tang J, Wang Y, Zhao W, Ye W, Zhou S (2019) Porous hollow carbon tube derived from kapok fibres as efficient metal-free oxygen reduction catalysts. Science China Technological Sciences 62:17101718

39. Wang Y, Zhang M, Fu J, Li T, Wang J, Fu Y (2016) Insights into the interaction between carbamazepine and natural dissolved organic matter in the Yangtze Estuary using fluorescence excitation-emission matrix spectra coupled with parallel factor analysis. Environ Sci Pollut Res 23:19887-19896. https://doi.org/10.1007/s11356-016-7203-2

40. Wu J, Zhao Y, Qi H, Zhao X, Yang T, Du Y, Zhang H, Wei Z (2017) Identifying the key factors that affect the formation of humic substance during different materials composting. Bioresour Technol 
244:1193-1196. https://doi.org/10.1016/j.biortech.2017.08.100

41. Xu W, Hu P, Zhou S, Li X, Li Y (2009) Electron shuttling function of dissolved organic matter. environmental science 30:2297-2301 (in Chinese)

42. Yang C, Zheng M, Zhang Y, Xi B, Tian Z, He X (2020) Bioreduction of hexavalent chromium: Effect of compost-derived humic acids and hematite. Chin Chem Lett 31:2693-2697.

https://doi.org/10.1016/j.cclet.2020.04.001

43. Yuan Y, Tan W, He X, Xi B, Gao R, Zhang H, Dang Q, Li D (2016) Heterogeneity of the electron exchange capacity of kitchen waste compost-derived humic acids based on fluorescence components. Anal Bioanal Chem 408:7825-7833. 10.1007/s00216-016-9885-1

44. Yuan Y, Tao Y, Zhou S, Yuan T, Lu Q, He J (2012) Electron transfer capacity as a rapid and simple maturity index for compost. Bioresour Technol 116:428-434.

https://doi.org/10.1016/j.biortech.2012.03.114

45. Yuan Y, Xi B, He X, Tan W, Gao R, Zhang H, Yang C, Zhao X, Huang C, Li D (2017) Compost-derived humic acids as regulators for reductive degradation of nitrobenzene. J Hazard Mater 339:378-384. https://doi.org/10.1016/j.jhazmat.2017.06.047

46. Zang B, Li S, Michel F, Li G, Luo Y, Zhang D, Li Y (2016) Effects of mix ratio, moisture content and aeration rate on sulfur odor emissions during pig manure composting. Waste Manag 56:498-505. https://doi.org/10.1016/j.wasman.2016.06.026

47. Zhang C, XI B, Zhang Q, Zhao Y, Wei Z, Jiang Y, Su J, Hu C (2021) Application status and prospect of compost in soil remediation and quality improvement.Environmental Engineering,1-15.(in Chinese)

48. Zhang Q, XI B, YANG J, Li S, Li X, Zhao X (2021) Structural characteristics of fulvic acid composted with different materials. China Environmental Science 41:763-770 (in Chinese)

49. Zhao X, Tan W, Peng J, Dang Q, Zhang H, Xi B (2020) Biowaste-source-dependent synthetic pathways of redox functional groups within humic acids favoring pentachlorophenol dechlorination in composting process. Environ Int 135:105380

50. Zhou S, Zhang Y, Huang T, Liu YF, Zhang L, Li G, Yue L, Luo X (2019) Spectral characteristics and sources of dissolved organic matter with different relative molecular weight from rainwater from summer and autumn in thezhoucun reservoir based on UV-Vis and EEMs. Environmental Science 40:172-184 (in Chinese)

51. Zhou Y, Selvam A, Wong JWC (2014) Evaluation of humic substances during co-composting of food waste, sawdust and Chinese medicinal herbal residues. Bioresour Technol 168:229-234. https://doi.org/10.1016/j.biortech.2014.05.070

\section{Figures}


(a)

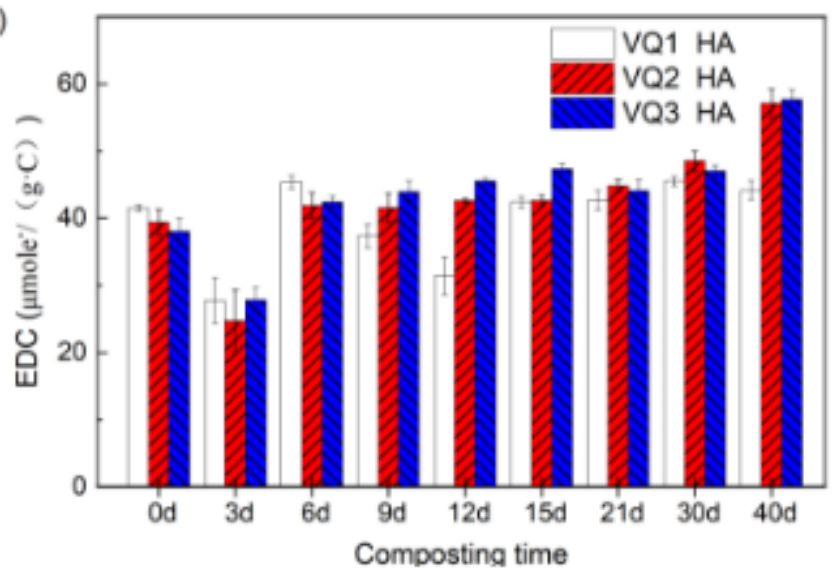

(c)

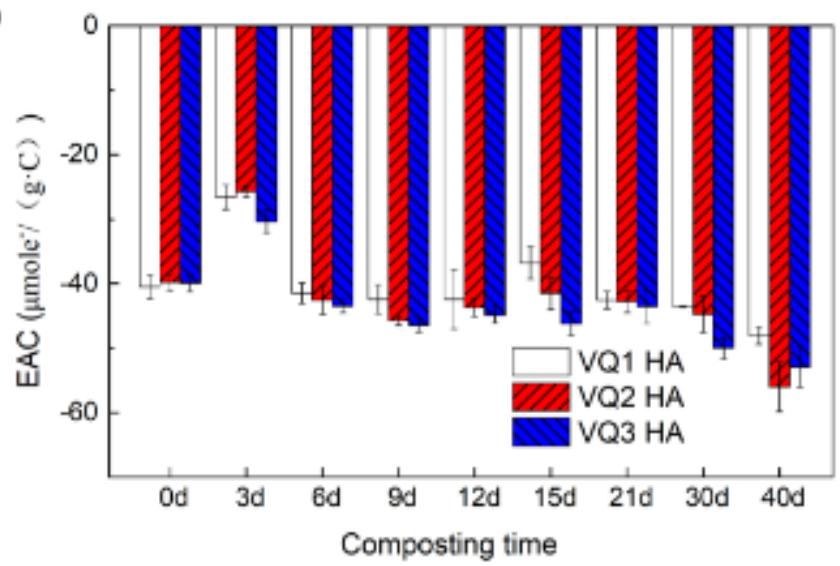

(e)

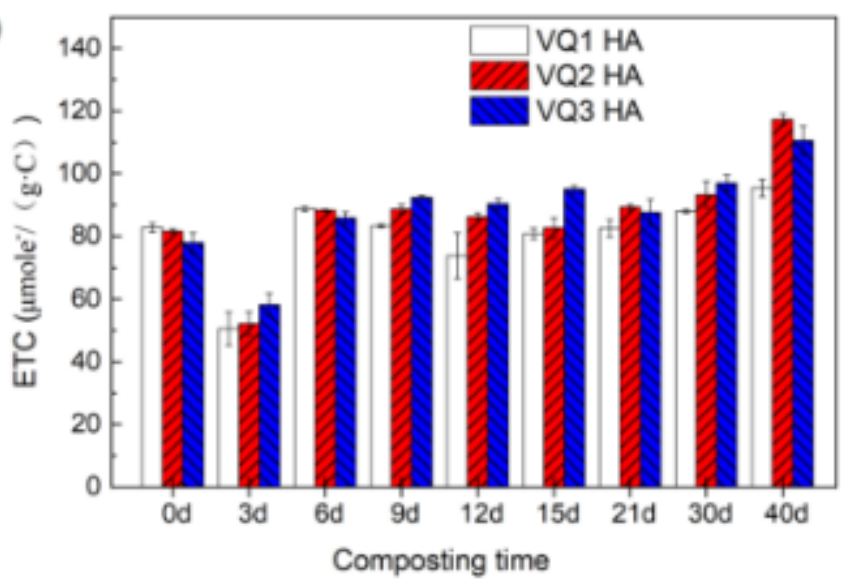

(b)

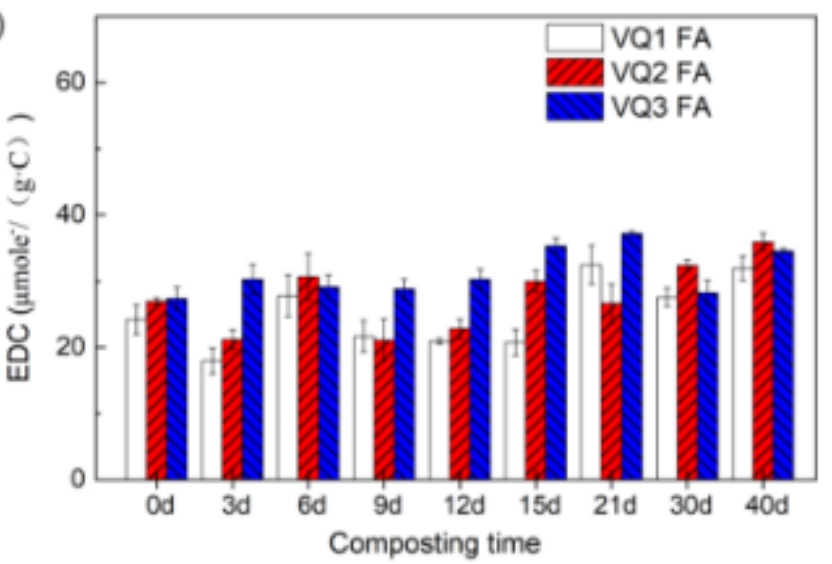

(d)

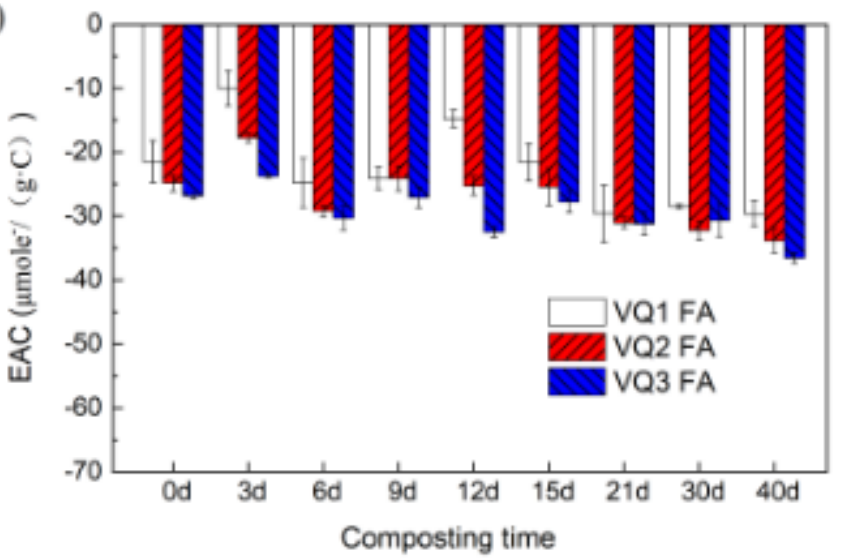

(f)

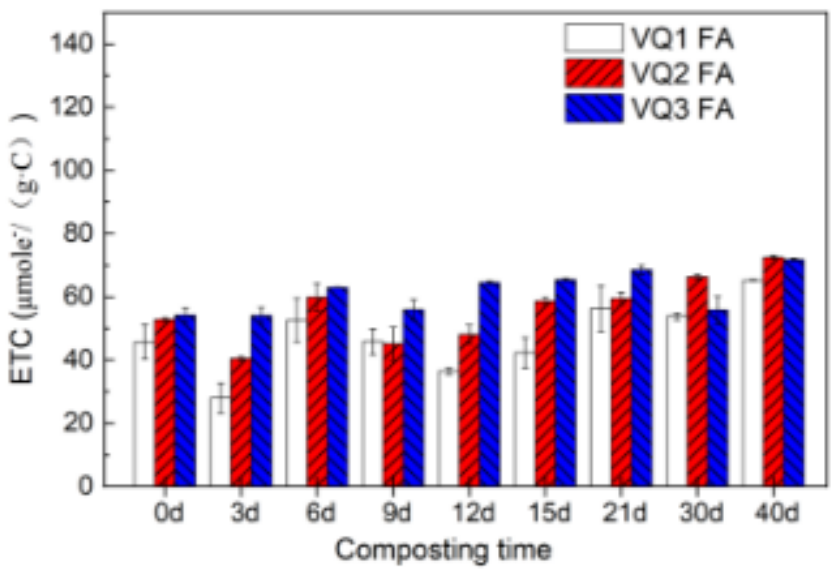

Figure 1

Changes in $\operatorname{EDC}(a, b), \operatorname{EAC}(c, d)$ and $\operatorname{ETC}(e, f)$ of HA and FA at different stages of compost 
(a)

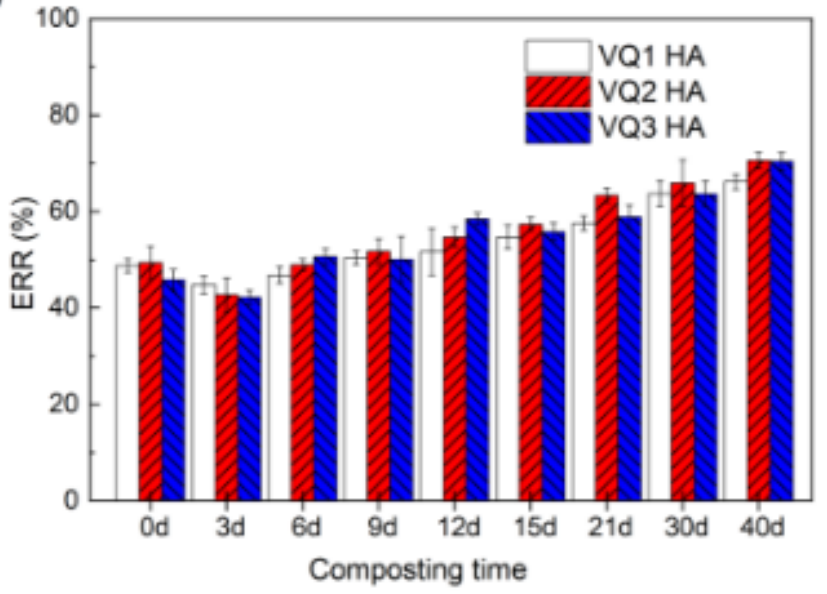

(b)

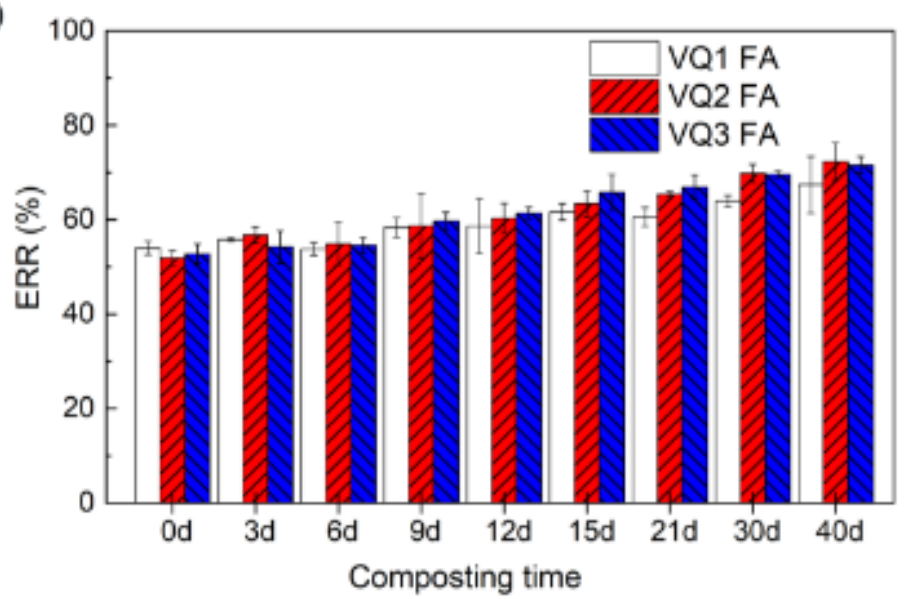

Figure 2

Changes in ERR of HA (a) and FA (b) at different stages of compost 

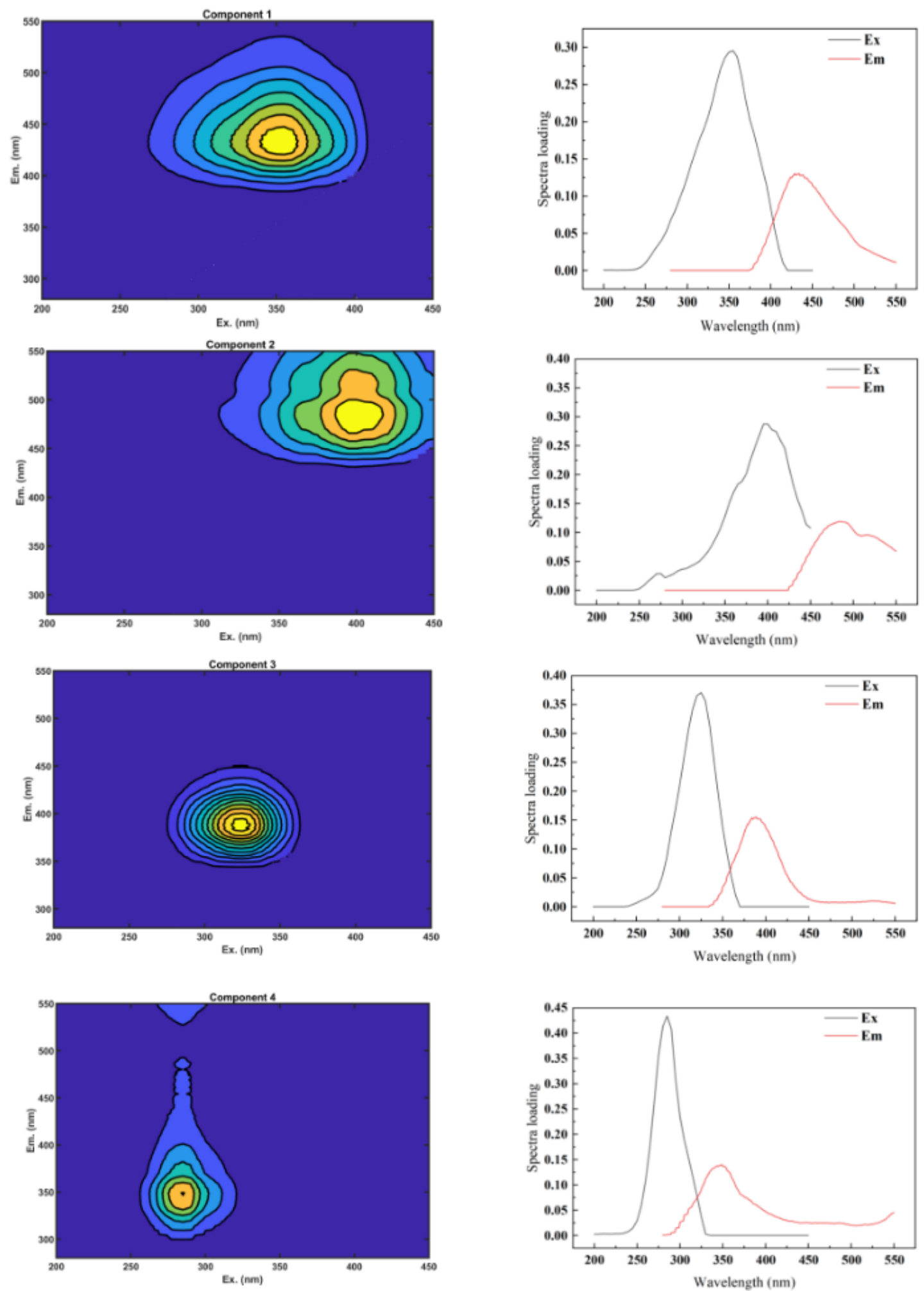

Figure 3

Overview of each component and related fluorescence load obtained after three-dimensional fluorescence parallel factor analysis 
(a)

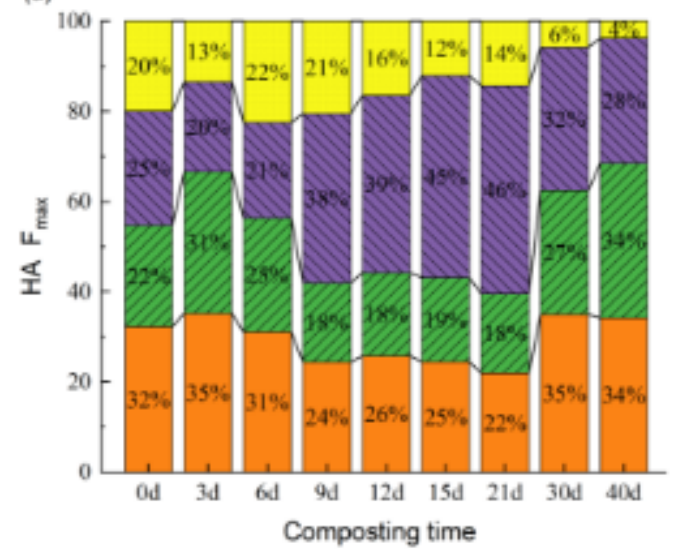

(c)

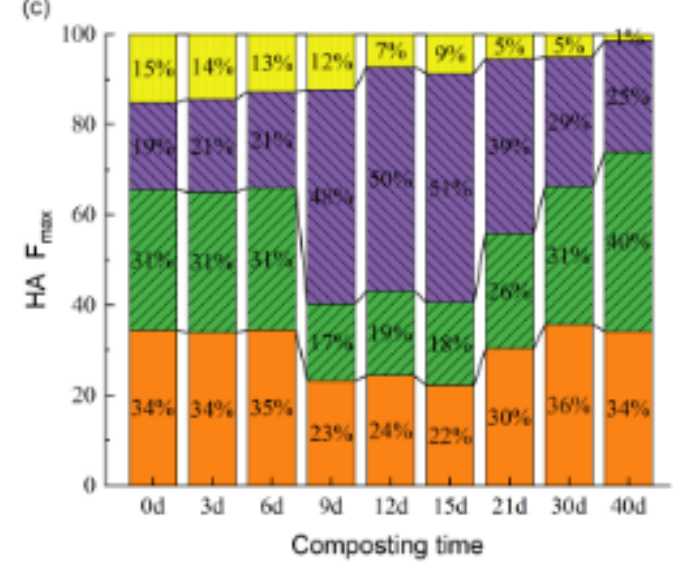

(e)

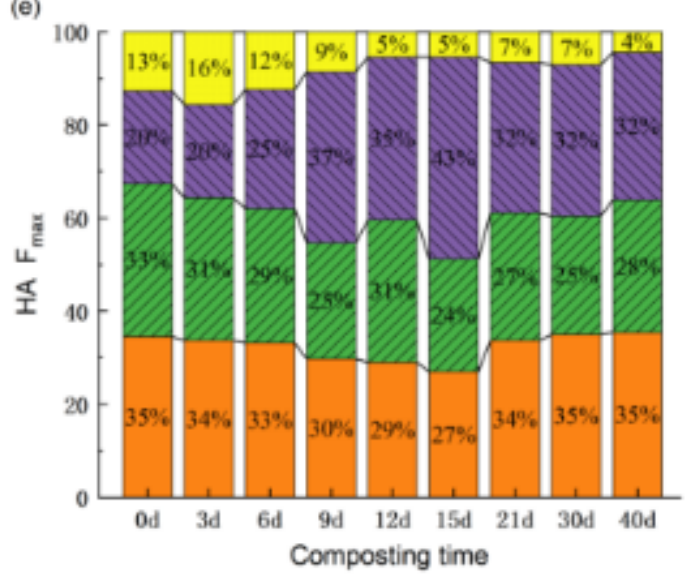

(b)

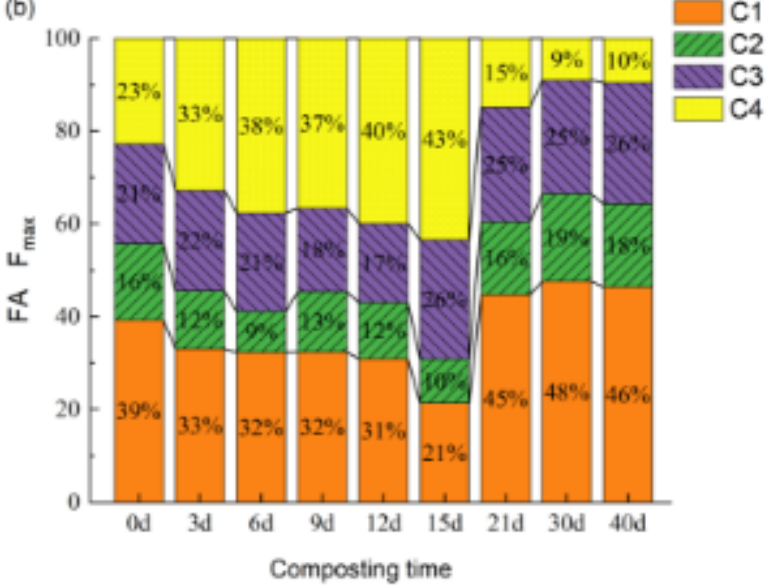

(d)

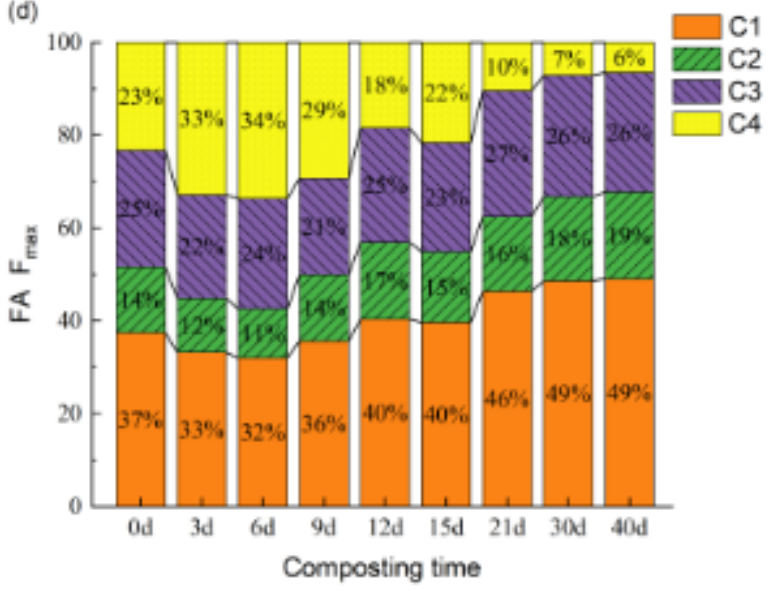

(f)

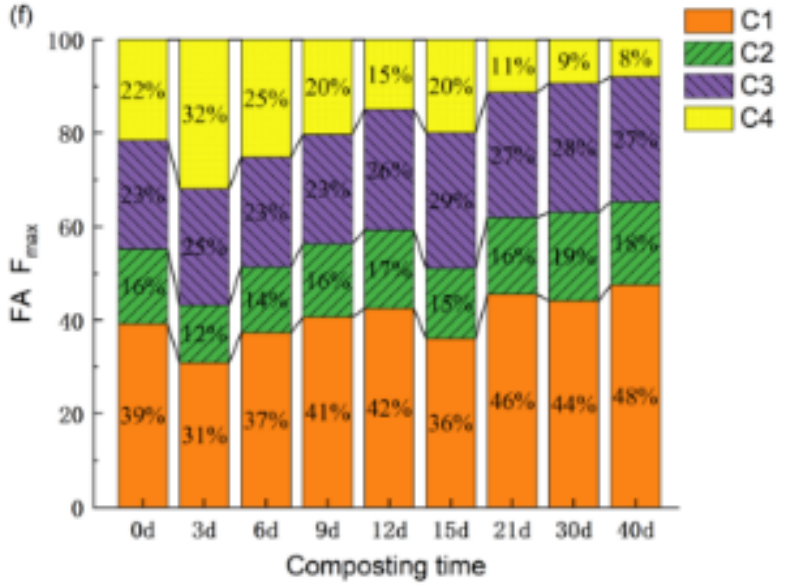

Figure 4

Changes in the proportion of HA and FA in each stage of compost humic substances :VQ1 (a, b); VQ2 (c, d); $\operatorname{VQ3}(e, f)$ 
(a)

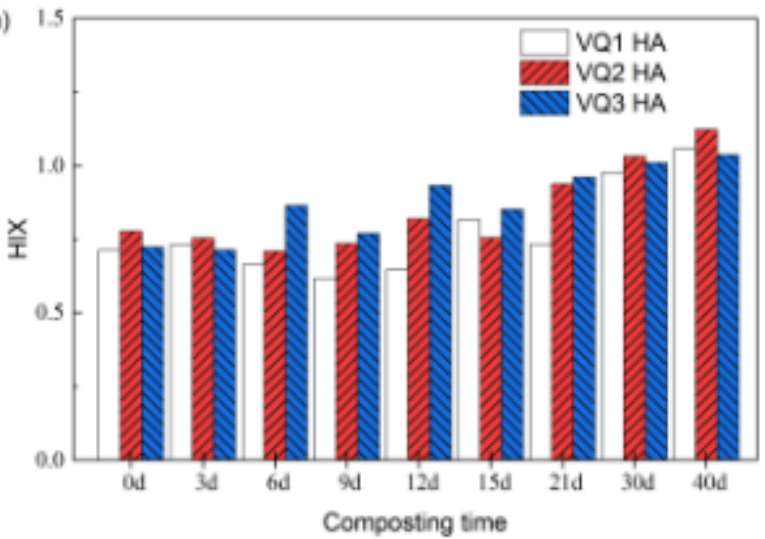

(c)

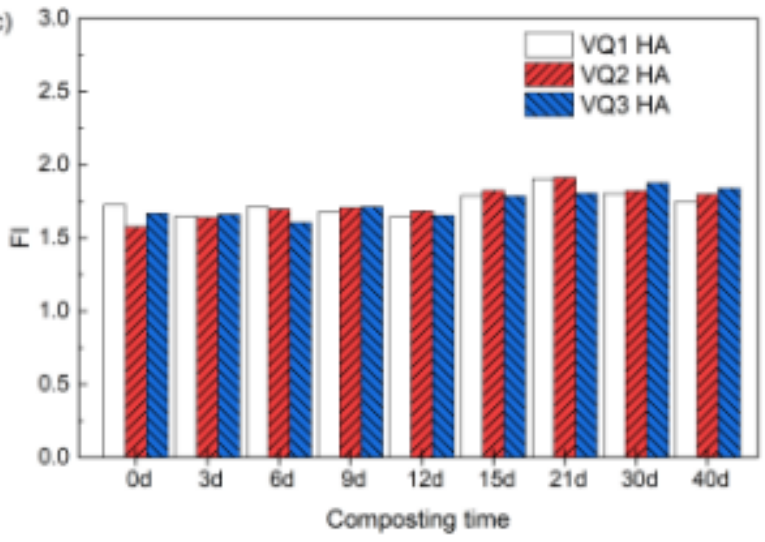

(b)

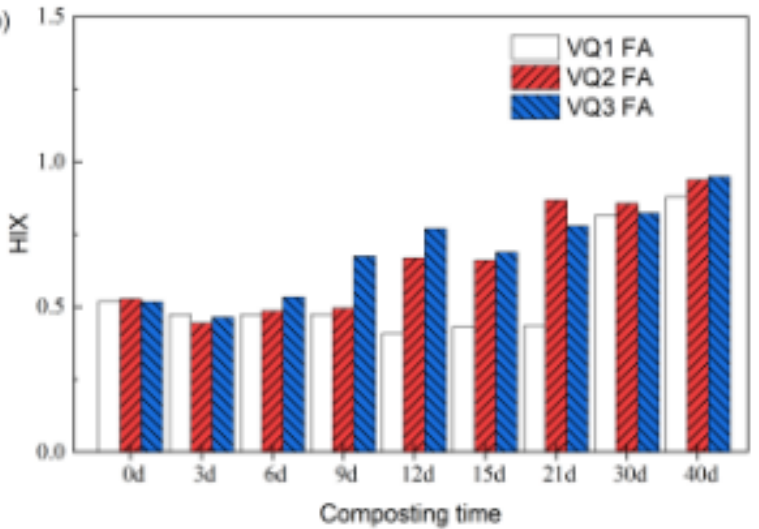

(d)

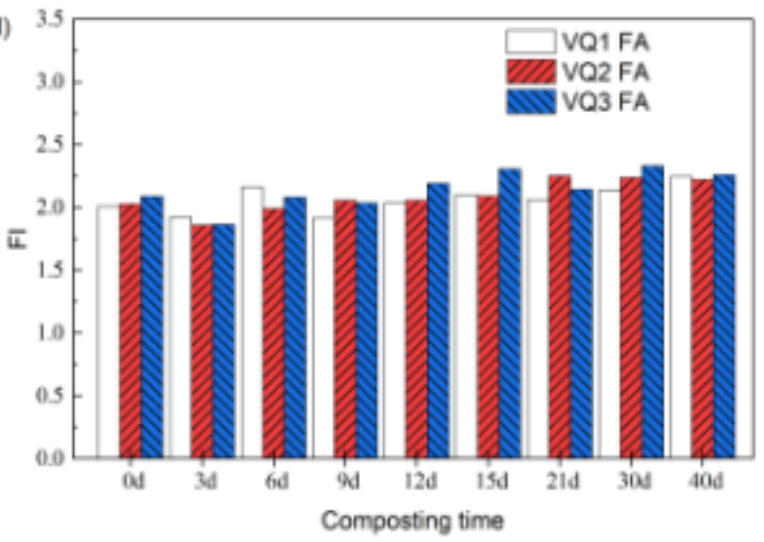

Figure 5

Changes of $\mathrm{HIX}$ index of $\mathrm{HA}(\mathrm{a})$, FA (b) and FI index of HA (c), FA (d) in compost humic substances 
(a)

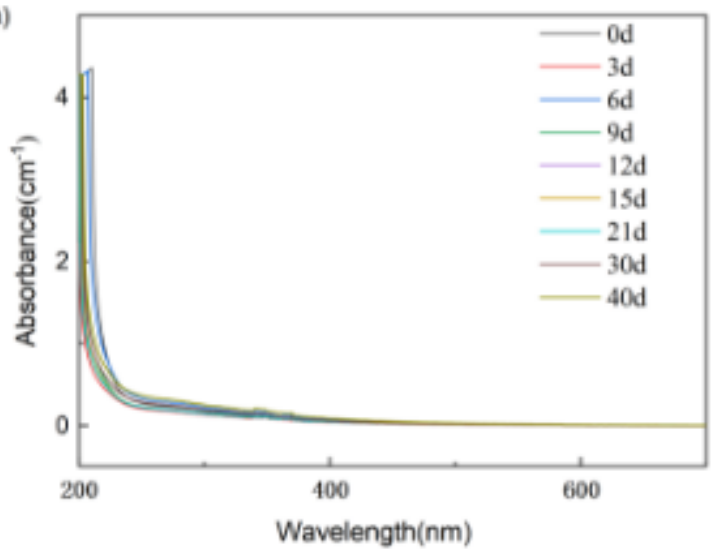

(c)

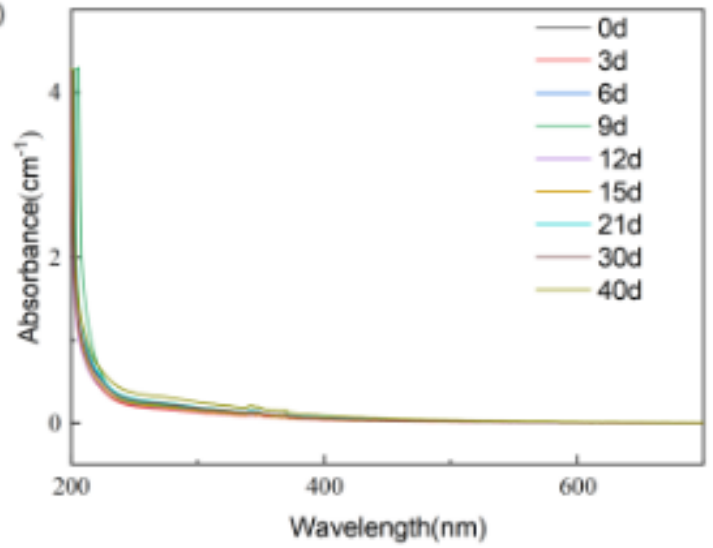

(e)

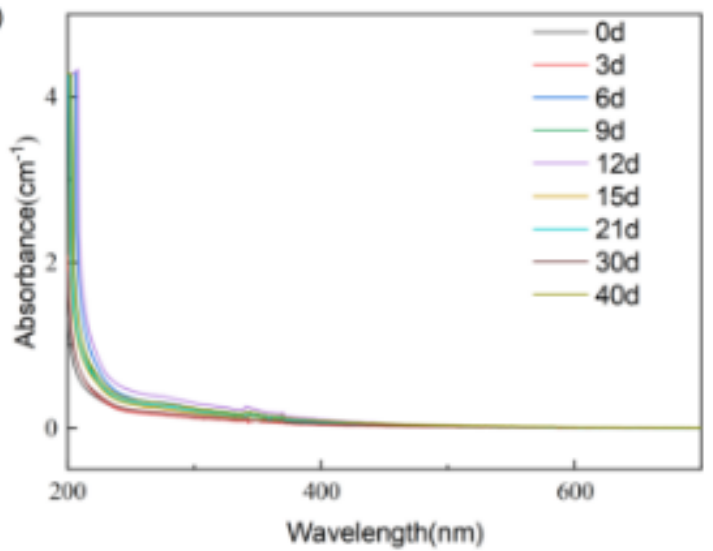

(b)

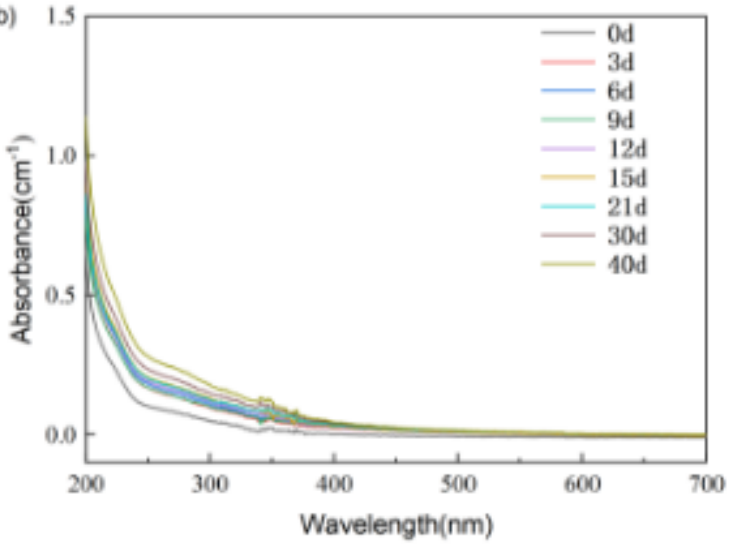

(d)

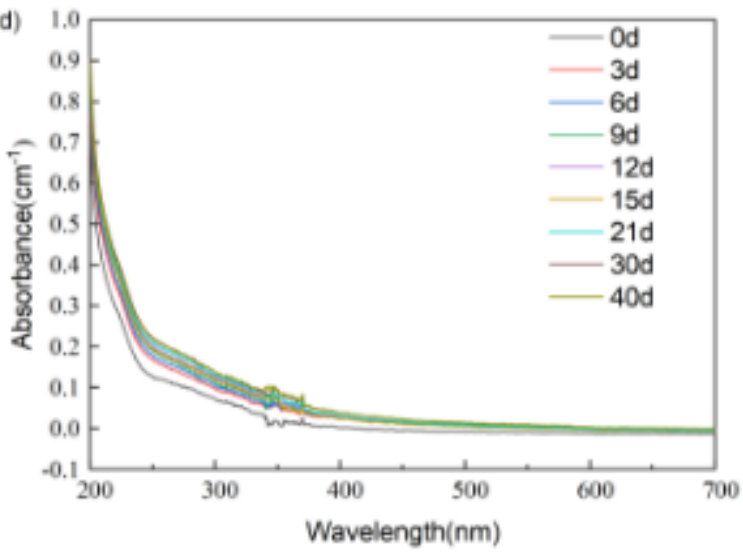

(f)

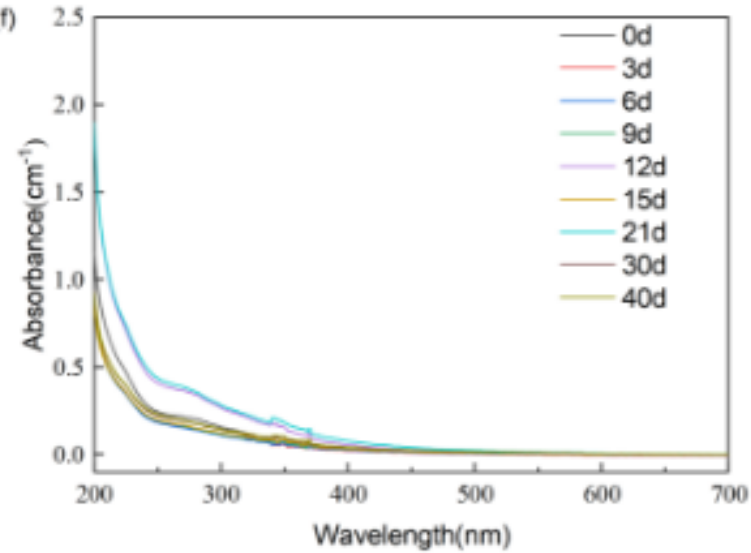

Figure 6

UV-Vis spectrum of HA and FA: VQ1 $(a, b)$; VQ2 $(c, d)$; VQ3 $(e, f)$ in sludge compost humic substances 

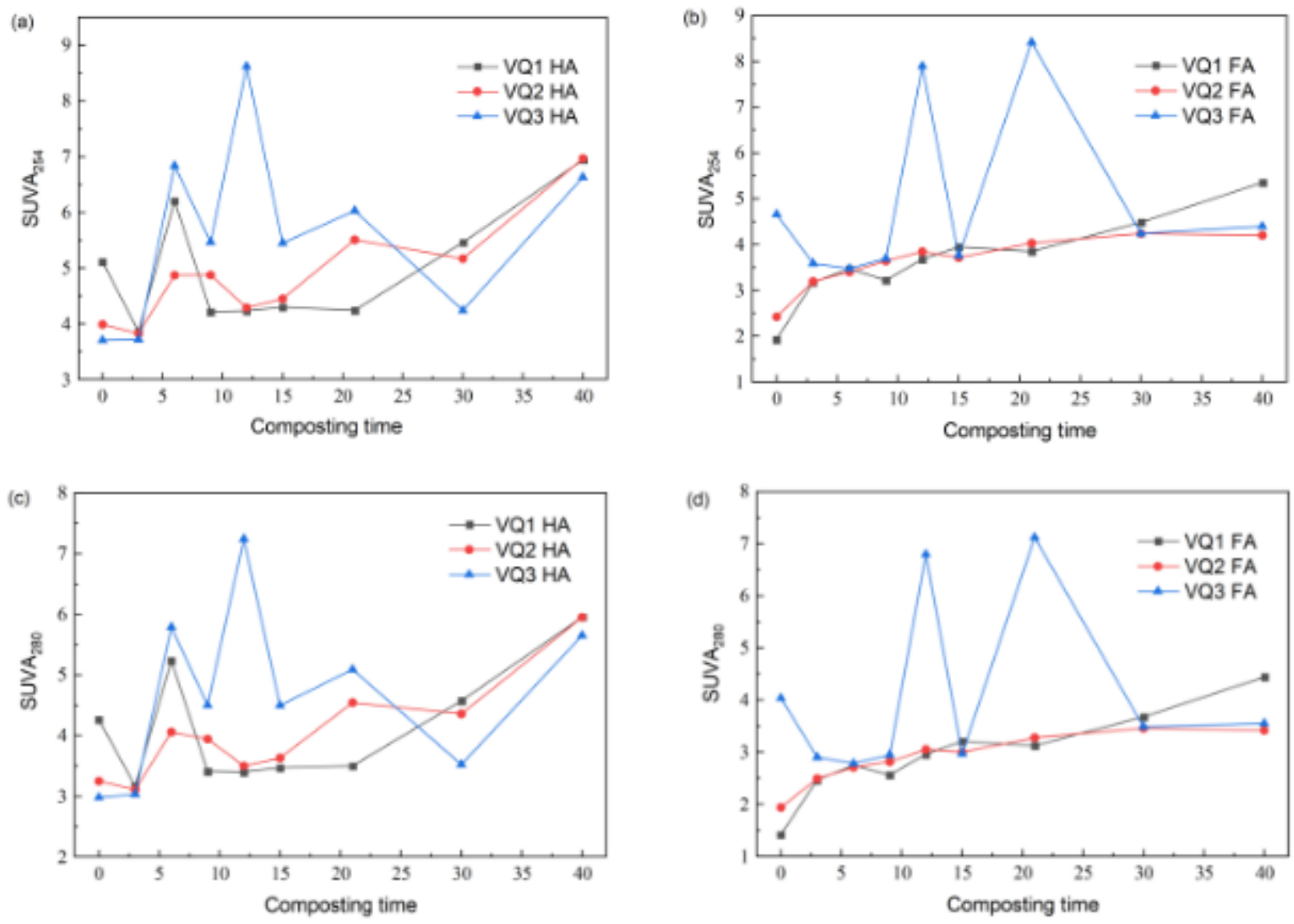

Figure 7

SUVA $_{254}$ of HA(a), FA (b) and SUVA 280 of $\mathrm{HA}(\mathrm{c}), \mathrm{FA}(\mathrm{d})$ in compost humic substances 

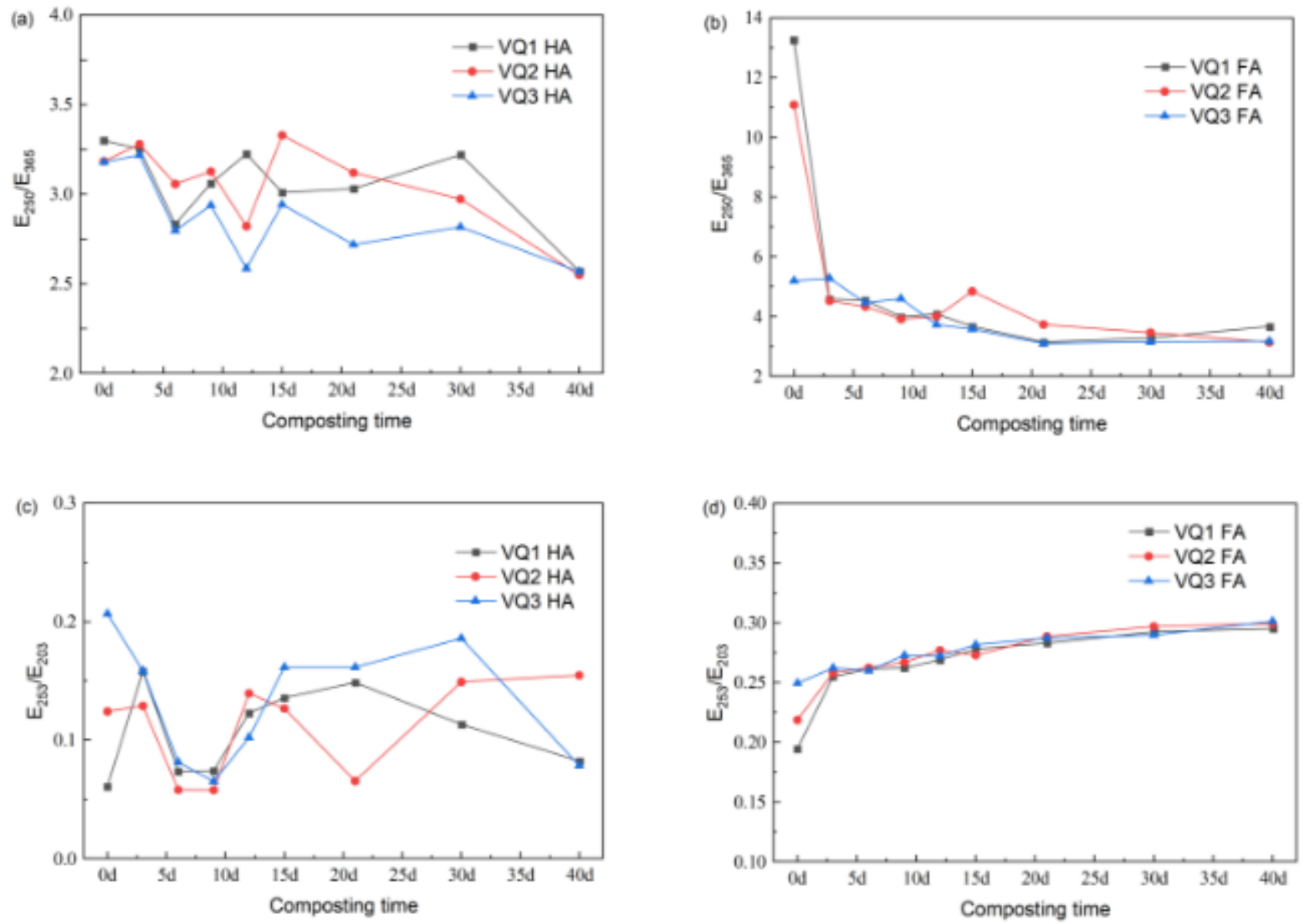

\section{Figure 8}

$E_{250} / E_{365}$ of $\mathrm{HA}(\mathrm{a}), \mathrm{Fa}(\mathrm{b})$ and $\mathrm{E}_{253} / \mathrm{E}_{203}$ of $\mathrm{HA}(\mathrm{c}), \mathrm{Fa}(\mathrm{d})$ in compost humic substances
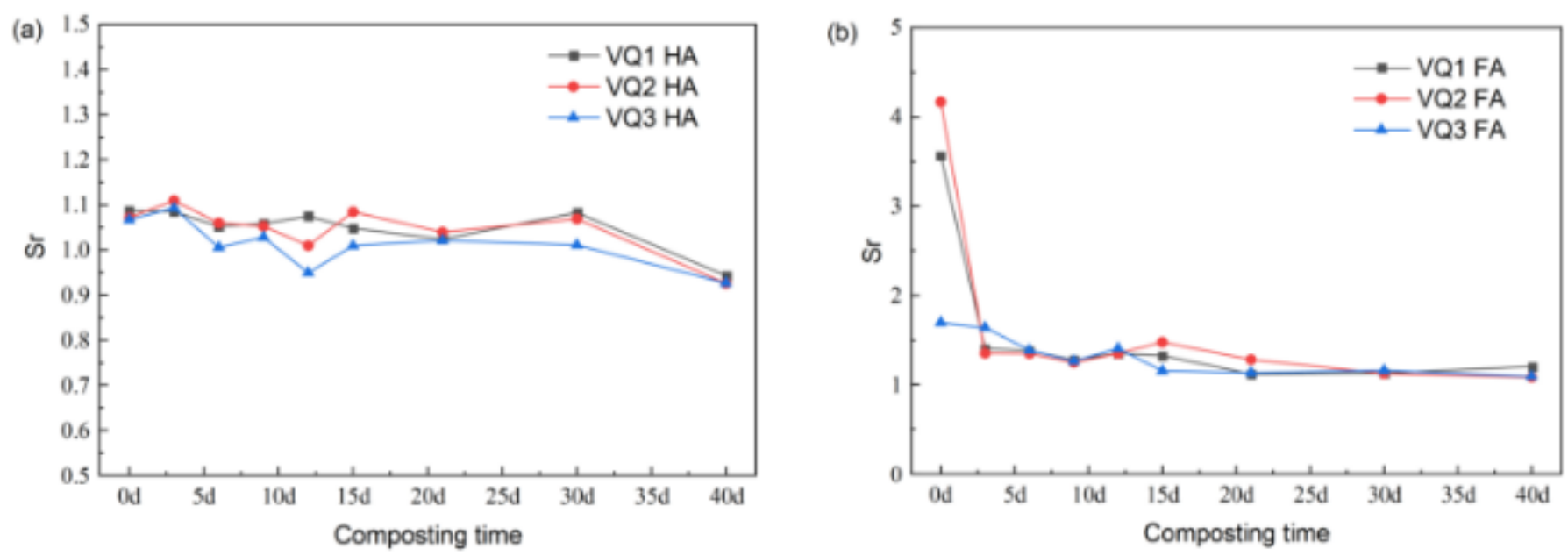

\section{Figure 9}

Sr variation of $\mathrm{HA}(\mathrm{a})$ and $\mathrm{FA}(\mathrm{b})$ in compost humic substances 
(a)

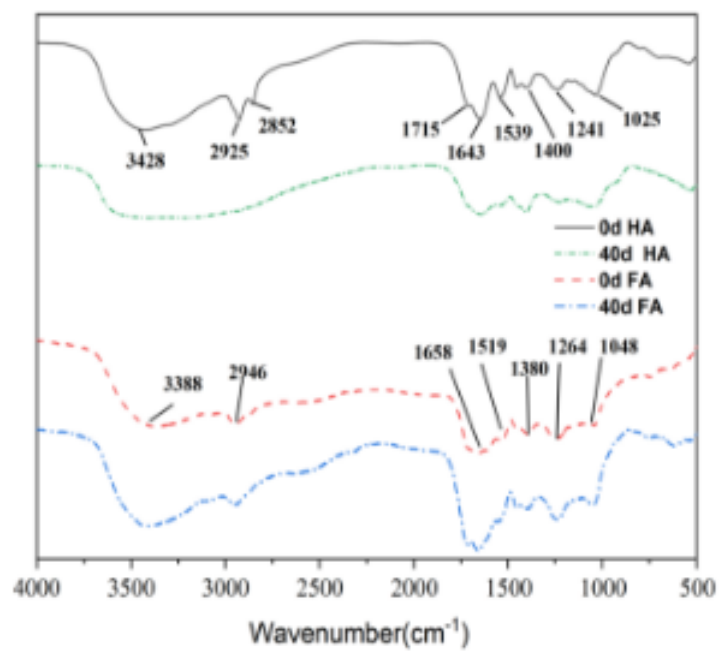

(b)

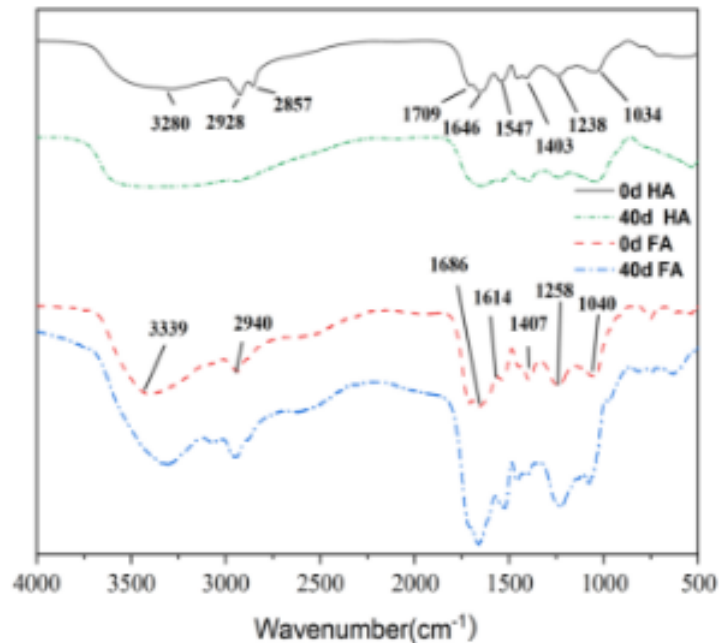

(c)

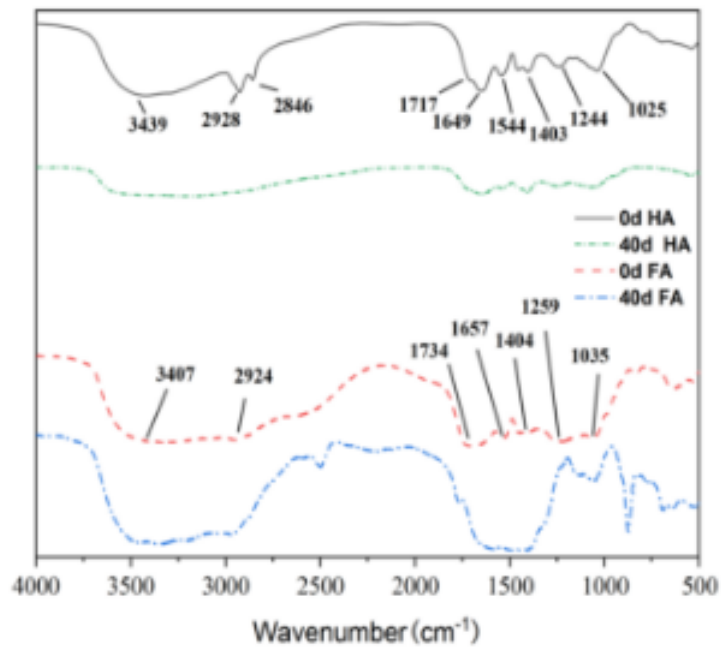

Figure 10

Infrared spectra of HA and FA of VQ1 (a), VQ2(b), VQ3(c) in compost humic substances 
(a)

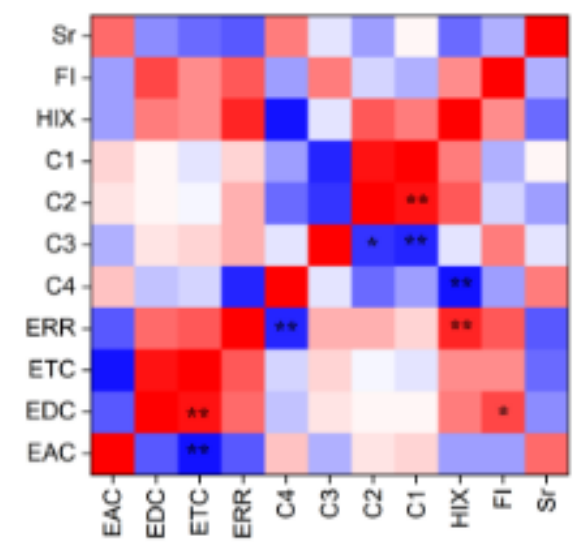

(c)

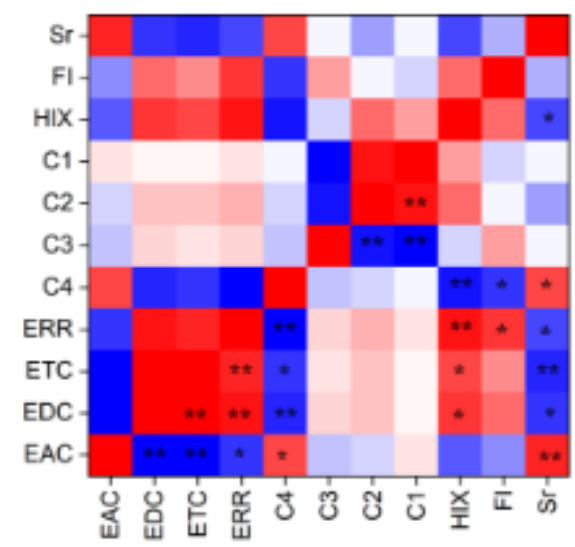

(e)

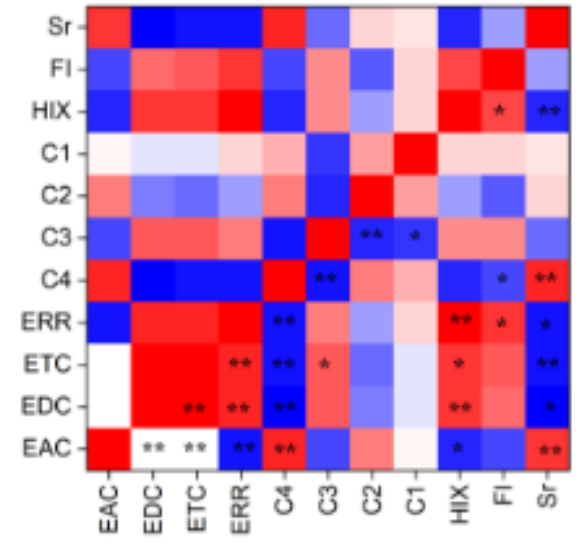

(b)

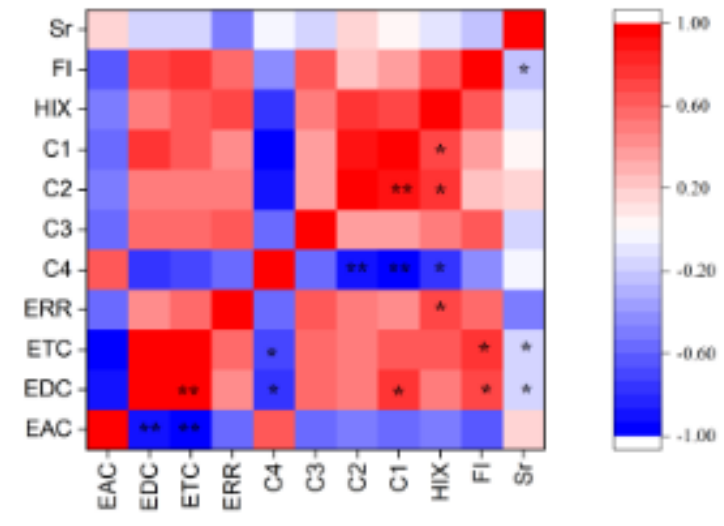

(d)

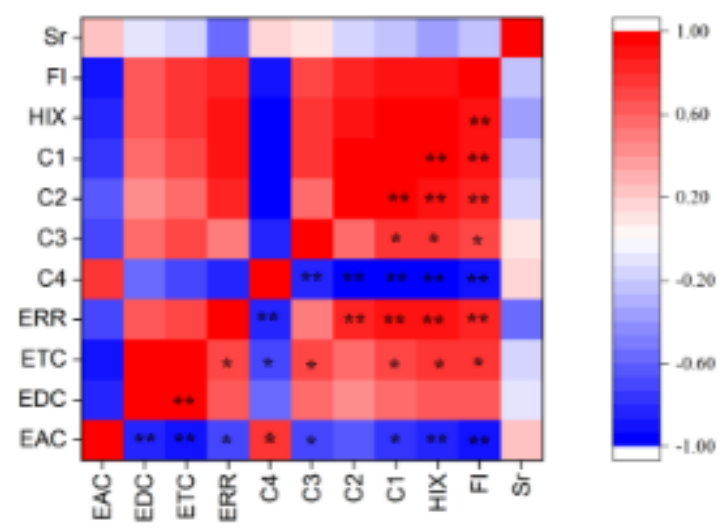

(f)

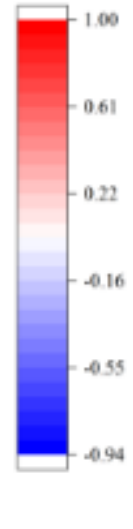

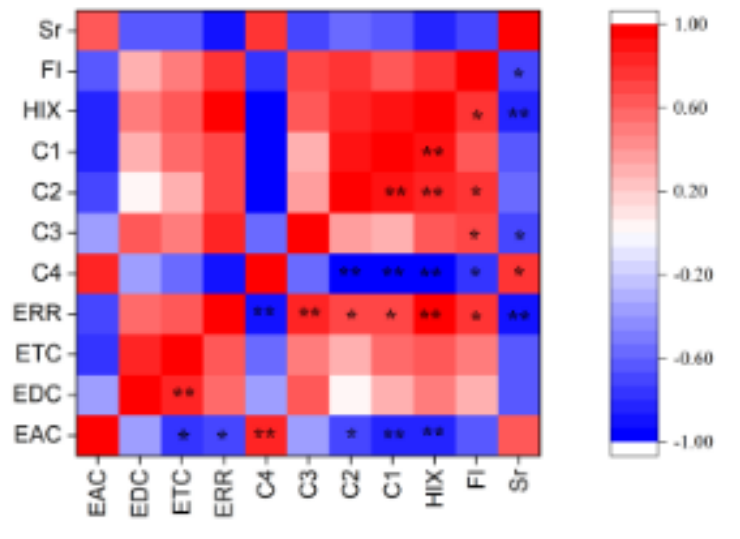

Figure 11

Heat map of correlation between HA and FA components and fluorescence electrochemical indices in VQ1, VQ2, VQ3 